\title{
CEPA
}

Center for Economic Policy Analysis

\section{Social Security in a Classical Growth Model}

Thomas R. Michl (Colgate University)

Duncan K. Foley (New School University)

CEPA Working Paper Series II

Economic Policy Analysis

Working Paper No. 11

June 2000, revised September 2001

Center for Economic Policy Analysis

New School University

80 Fifth Avenue, Fifth Floor, New York, NY 10011-8002

Tel. 212.229.5901 • Fax 212.229.5903

www.newschool.edu/cepa 


\title{
Social Security in a Classical Growth Model
}

\author{
Thomas R. Michl \\ Duncan K. Foley \\ Department of Economics \\ Department of Economics \\ Colgate University \\ Graduate Faculty \\ 13 Oak Drive \\ New School University \\ Hamilton, NY 13346 \\ 65 Fifth Avenue \\ (315)-228-7526 \\ New York, NY 10003 \\ tmichl@nycap.rr.com \\ (212)-229-5906/5717 \\ foleyd@newschool.edu
}

September 9, 2001 


\begin{abstract}
Social Security in a Classical Growth Model

by Thomas R. Michl and Duncan K. Foley

JEL E1, E6
\end{abstract}

Keywords: Overlapping generations growth, social security, Pasinetti

paradox. 
This paper develops a growth model with overlapping generations of workers who save for life-cycle reasons and Ricardian capitalists who save from a bequest motive. The population of workers accommodates growth, so that the rate of capital accumulation is endogenous and determines the growth of employment. Two regimes are possible, one in which workers' saving dominates the long-run and a second in which the long-run equilibrium growth rate is determined completely by the capitalist saving function, sometimes called the Cambridge equation. The second regime exhibits a version of the Pasinetti Paradox: changes in workers' saving affect the level, but not the growth rate, of capital in the long run. Applied to social security, this result implies that an unfunded system relying on payroll taxes reduces workers' lifetime wealth and saving, creating level effects on the capital stock without affecting its long-run growth rate. These effects are mitigated by the presence of a reserve fund, various levels of which are examined. Calibrating the model to realistic parameter values for the U.S. facilitates an interpretation of the controversies over the percentage of the national wealth originating in life-cycle saving and the effects of social security on saving. The model is offered as an analytical framework for the review of current topics in fiscal policy, in particular identifying the social security reserve fund as a potential vehicle for generating capital accumulation and effecting a progressive redistribution of wealth. 


\section{Introduction}

The question of the impact of social security systems ${ }^{1}$ on capital accumulation and growth is a central issue in the ongoing policy debates over social security reform. In this paper, we attack this question in the context of a Classical growth model that incorporates life-cycle saving by overlapping generations of workers as well as dynastic saving by capitalists with an infinite horizon, and that takes economic growth to be unconstrained by the availability of labor and therefore endogenous. In this model the growth rate of worker households in each period is determined by the growth rate of the capital stock in order to keep the (real) wage invariant at an exogenously given level. Thus even though each household's supply of labor is inelastic to the wage in each period, the aggregate supply of labor always adjusts to keep the wage constant. (For the sake of analytical simplicity we abstract from changes in the efficiency of labor. When there is pure labor-augmenting technical progress, the assumption of a given wage must be replaced by the assumption of a given wage share, or efficiency wage.) Under the assumption of an exogenously given wage (or wage share in output) the capital intensity of the technique of production and the profit rate are invariant in the short run as well as the long run. Since the saving of capitalist households depends on the relation of the profit rate to their rate of time preference, the growth of the capital stock, output, and employment are also determined in the Classical framework by the exogenously given wage.

The neoclassical literature has come to recognize that aggregate accu-

mulation will be determined by the saving of the most "patient" class of households (Smetters, 1999). In the Classical framework the capitalists are 
in general the most patient class. In this respect there is a convergence of neoclassical and Classical approaches. Another hallmark of the Classical approach, however, is its theory of population. The Classical economists see population growth as an endogenous response to the accumulation of capital. Thus Classical economic growth is inherently endogenous in the language of contemporary growth theory. The Classical theory takes the distribution of income rather than the rate of growth of population as exogenous. This difference is at the root of the controversies between the two approaches concerning the source and determinants of profits (Marglin, 1984).

In the context of the analysis of the impact of social security systems on saving and growth, the different treatment of population growth in the neoclassical and Classical models leads to a fundamental difference in the predicted growth path. Neoclassical models, as a result of their emphasis on diminishing returns to capital accumulation in the face of exogenously given labor force growth, typically envision the growth rate of output declining over time to match the growth rate of the population. The Classical model, in sharp contrast, envisions the growth rate of the labor force rising over time to match the exogenously determined growth rate of the capital stock. This difference has important consequences for the prediction of the actuarial solvency of social security systems and their impact on the class distribution of wealth. We study these questions in detail below.

Thus the analysis of the Classical model can help clarify the empirical literature on the effects of social security wealth on saving. Martin Feldstein, in his seminal paper (Feldstein, 1974) and subsequent work, interprets the finding that social security reduces saving from the perspective of an overlap- 
ping generations model in the tradition of Paul Samuelson (1958) and Peter Diamond (1965). Economists who dispute the size or existence of this replacement effect have traditionally appealed to alternative motives for saving, such as the bequest motive. Although it is well-known that the theoretical effect of social security on net saving is indeterminate in a life-cycle model because of the offsetting influence of social security on retirement $\operatorname{age}^{2}$, the accumulated empirical evidence lends some support to the argument that social security does have a net negative effect on saving. For example, a recent survey of this literature conducted by the Congressional Budget Office (1998) reports that 12 out of 14 studies using cross-sectional household data find that each dollar of social security wealth reduces private wealth, generally by 50 cents or less. The two studies that find positive effects lend some support to the twoclass hypothesis. The first (David and Menchik, 1985) uses probate records, which probably selects for wealthier than average individuals. The second (Gullason et al., 1993) finds that among households in the 1983 Survey of Consumer Finances, social security wealth has an insignificant positive effect on total fungible wealth but a significant negative effect on pension wealth when that asset category is segregated from the rest. This supports the claim of Munnell (1974) that it is necessary to separate "retirement saving" from total saving because the life-cycle theory applies more precisely to the narrower category. In the two other study designs employed by researchers, time series and international cross-sectional, no clear consensus about the effects of social security on saving has emerged. Partly this may be explained by methodological, conceptual, and measurement problems. But one might also speculate that the mixed results arise because these studies use national in- 
come accounting definitions - household, private, or national saving - which combine saving out of profits, where the bequest motive is concentrated, with saving out of labor income, where life cycle saving predominates. In sum, the empirical literature on the effects of social security on wealth formation points toward theoretical models recognizing the co-existence of life-cycle and bequest motives for saving, for which the Classical approach would seem a natural choice.

In section 2 we set up the Classical model with a social security system. From the Classical point of view, the first question that must be addressed is whether capitalist saving does indeed dominate social saving. Paul Samuelson and Franco Modigliani, responding to Luigi Pasinetti's discovery (the "Pasinetti paradox") that worker saving does not affect the profit rate in a model with exogenous labor force growth regardless of the workers' propensity to save or the marginal product of capital, observed that the mounting wealth of a very thrifty working class could reduce the capitalists to irrelevance $^{3}$. In section 3 we consider this question, and suggest that for realistic empirical estimates of the crucial parameters for the U.S. economy, Pasinetti's paradox will hold. The remainder of the paper studies the impact of social security systems on social saving and the distribution of wealth between worker and capitalist households under various assumptions on the method of funding social security. We find that an unfunded social security system has an impact on worker households' wealth that ranges from modest to substantial. A fully funded or over-funded social security system could be an important vehicle for the redistribution of wealth from capitalist to worker households. 


\section{A General Model of Growth}

We begin by developing a general model of growth with overlapping generations of workers, a social security system, and a class of dynastic capitalists. We then work through five special applications: a basic model with no social security system, in which the dualism of the model is particularly transparent; a model of unfunded ("pay-as-you-go") social security; a model of partially funded social security; a model of fully funded social security; and finally, a somewhat speculative model of a superfunded system (defined below). All the models in this paper are set in discrete time, and the time subscript on dated variables will be left implicit to minimize clutter. Thus, for the capital stock at time $t+1$ or $t-1$ we will write $K_{+1}$ or $K_{-1}$. All the models are one-sector "corn" models which assume that output can be either consumed or accumulated as capital stock.

\subsection{Capital Accumulation}

Workers are assumed to live for two periods, working for the wage in the first period, then retiring and living off the wealth accumulated during their working career, plus any social security benefits. All the agents in our model, capitalists and workers, are assumed to maximize a discounted logarithmic utility function. We will define the discount factor to be $\beta_{c}$ for capitalists and $\beta$ for workers (to simplify notation). Workers are distinguished by their lack of a bequest motive, and thus constitute the life-cycle savers, while capitalists are members of infinitely-lived dynasties which reproduce themselves over time through intergenerational transfers of wealth. This behavioral com- 
partmentalization lets us calibrate the model below to the observed range of estimates for the proportion of wealth in the U.S. that originated in life-cycle saving.

\subsubsection{Capitalists}

Capitalists solve a constrained optimization problem over an infinite time horizon, discounting consumption by the factor $\beta_{c}\left(0<\beta_{c}<1\right)$. The usual explanation for such dynastic behavior is that each generation cares about its offspring, becoming linked across time and behaving like one infinitelylived household. This may not be the primary reason that households in the wealthiest percentiles (where real capitalists can be found) accumulate so diligently. This modelling assumption is a convenient analytical device for introducing a structural component to social saving which is proportional to wealth, whether the locus of this structure is the capitalist firm or the capitalist household in reality. Capitalists' end-of-period wealth consists of undepreciated capital plus gross end-of-period profits. The net rate of profit after depreciation is denoted $r$. We assume that the number of capitalist households remains constant, and we normalize it to one. The capitalist programming problem in period 0 is to choose consumption levels, $C$, so as to

$$
\begin{gathered}
\max \left(1-\beta_{c}\right) \sum_{t=0}^{\infty} \beta_{c}{ }^{t} \ln C \\
\text { subject to } C+K_{+1}^{c} \leq(1+r) K^{c} \\
\text { given } K_{0}^{c}, r
\end{gathered}
$$


The solution can be obtained relatively easily, and as is well known turns out to have a straightforward form ${ }^{4}$. Capitalists consume a constant proportion of their end-of-period wealth, and save the rest. Their saving function is written as follows:

$$
K_{+1}^{c}=\beta_{c}(1+r) K^{c}
$$

A convenient mathematical expression of the capitalist saving function is the dynamic form which we will call the Cambridge equation ${ }^{5}$ :

$$
(1+g)=\beta_{c}(1+r)
$$

In this equation, $1+g$ represents the growth factor for capitalist wealth, $K_{+1}^{c} / K^{c}$, or one plus its growth rate. We elide any identifying superscript to reduce notational clutter. In order to find similar expressions for the growth of workers' wealth, we need to specify the dynamic fiscal policy in place.

\subsubsection{Workers}

Workers solve a two-period optimization problem, discounting consumption by the factor $\beta,(0<\beta<1)$. The present value of their consumption, comprising spending during their active period, $c^{w}$, and spending during retirement, $c^{r}$, cannot exceed their lifetime wealth, $h$. Their lifetime wealth consists of their wage, $w$, plus social security wealth. Social security wealth is the discounted value of the social security benefit, $b$, minus the lump-sum social security tax, $\tau$. Any saving they achieve during their active period earns interest at the market rate $r$. Thus, we write

$$
\max (1-\beta) \ln c^{w}+\beta \ln c^{r}
$$




$$
\begin{aligned}
& \text { subject to } c^{w}+\frac{c^{r}}{1+r} \leq h \\
& \text { where } h=w+\left(\frac{b}{1+r}-\tau\right)
\end{aligned}
$$

The solution can easily be obtained ${ }^{6}$. During their working period, workers will consume a constant fraction of their lifetime wealth.

$$
c^{w}=(1-\beta) h
$$

Individual worker saving is thus

$$
s^{w}=w-\tau-c^{w}=\beta w-\tau+(1-\beta)\left(\tau-\frac{b}{1+r}\right)
$$

Until we have specified the relationship between taxes and benefits, we can say little more about workers' saving.

\subsection{Dynamic Fiscal Policy}

The social security system operates a reserve fund which it invests in the capital market at the prevailing rate of profit. Government-owned capital is denoted $K^{G}$. Benefits are financed partly through the reserve fund and partly through payroll taxes. For consistency with taxes and benefits, we measure the reserve fund as $f=K^{G} / N$, on a per worker basis. At any given moment, the reserve fund will obey

$$
f=\frac{(1+r) f_{-1}-b_{-1}}{1+g_{-1}^{K}}+\tau
$$

where $g^{K}$ represents the growth rate of the aggregate capital stock. An increase in the growth rate of capital will reduce the reserve fund per worker in the next period because it increases the number of workers who are employed 
by the capital stock. Clearly the existence of a reserve fund necessitates a period of primitive accumulation during which taxes exceed benefits, and we return to this question after we have presented the whole model and its specialized cases.

We need to specify the government's policy targets and instruments. We choose to target a constant level of benefits $\left(b=b_{-1}\right)$ and a constant reserve fund $\left(f=f_{-1}\right)$, using the tax as the policy instrument. Following a well-established and sensible tradition, we restrict our attention to nondistortionary lump-sum taxes and benefits. The dynamic budget constraint for a government adopting these targets and instruments requires that

$$
\tau=\frac{b-f\left(r-g_{-1}^{K}\right)}{1+g_{-1}^{K}}
$$

Having committed the government to a policy of taxes, benefits, and government saving, we can deduce the effects on the worker households, whose lifetime wealth can now be written

$$
h=w-b\left(\frac{1}{1+g_{-1}^{K}}-\frac{1}{1+r}\right)+f\left(\frac{r-g_{-1}^{K}}{1+g_{-1}^{K}}\right)
$$

With this information in hand, we can characterize the growth of worker's asset holdings.

\subsection{Workers' Growth Factor}

Expressions for aggregate workers' saving, $K_{+1}^{w}$, corresponding to Equations

(1) and (2) for capitalist saving can be derived by multiplying individual worker saving, $s^{w}$, by employment, $N$. It is important to be aware that 
the level of employment is determined by the volume of capital accumulated in this model, rather than vice versa. Output is produced with a Leontief technology employing $k$ units of capital per worker, so that employment will given by

$$
N=\frac{K}{k}
$$

The aggregate capital stock is simply the sum $K^{c}+K^{w}+K^{G}$. The fiscal policy target $f$ ties the government-owned capital stock rigidly to the private capital stock since

$$
K^{G}=f N=\frac{f}{k-f}\left(K^{c}+K^{w}\right)
$$

Substituting Equations (3)-(7) gives us the expression for aggregate workers' saving we seek:

$$
\begin{gathered}
K_{+1}^{w}=a_{0} K=a_{0}\left(\frac{k}{k-f}\right)\left(K^{c}+K^{w}\right) \\
\text { where } a_{0}=\frac{w \beta}{k}-\frac{b}{k}\left(\frac{\beta}{1+g_{-1}^{K}}+\frac{1-\beta}{1+r}\right)+\frac{\beta f\left(r-g_{-1}^{K}\right)}{k\left(1+g_{-1}^{K}\right)}
\end{gathered}
$$

For expositional purposes, it is useful to define a variant of the consolidating term $a_{0}$ based on its value when the capital stock is growing at the rate dictated by the Cambridge equation, $g$, Let us call this value $\phi$ :

$$
\phi=\frac{w \beta}{k}-\frac{b}{k}\left(\frac{\beta}{1+g}+\frac{1-\beta}{1+r}\right)+\frac{\beta f(r-g)}{k(1+g)}
$$

The synthetic term $\phi$ is the workers' growth factor, representing the steady state ratio between workers' saving and the total capital stock. This term proves useful in characterizing the distribution of wealth in the steady state. 


\subsection{Closing the Model}

Classical economists like Adam Smith or David Ricardo regarded the wage as determined by social and historical factors that lay outside the market, and they regarded the supply of labor as quite flexible, for example because of the demographic factors most often associated with Thomas Malthus or the labor reserves associated with Karl Marx. We accept this framework as a first approximation by assuming that the real wage, $w$, is given exogenously ${ }^{7}$, and that the population of workers accomodates growth:

$$
w=\bar{w}
$$

Given the wage, the profit rate depends upon the technique of production in actual use, which we will take as given and unchanging ${ }^{8}$. In a onecommodity system, the technique is described by any two of three parameters: labor productivity (or the output-labor ratio), $x$, capital productivity (or the output-capital ratio), $\rho$, and capital intensity (or the capital-labor ratio), $k$. It is also useful to define the gross profit share, $\pi=1-w / x$. The determination of $r$, the net rate of profit (the gross profit rate after depreciation, $\delta$ ) follows directly from the wage-profit equation, or

$$
r=\frac{x-w}{k}-\delta=\pi \rho-\delta
$$

We have now got a complete model, with Equations (1), (8), (10), and (11) determining in each period the endogenous variables $w, r, K_{+1}^{c}$, and $K_{+1}^{w}$ given the exogenous parameters and the past history of capital accumulation. The trajectory for capitalist wealth is trivial, since it follows Equation (1) 
mechanically. Similarly, the trajectory for government-owned capital is fully determined by that of private capital through Equation (7). The trajectory for workers' wealth obeys the second-order difference equation:

$$
\begin{gathered}
K^{w}+a_{1} K_{-1}^{w}+a_{2} K_{-2}^{w}=A_{0}(1+g)^{t} \\
\text { where } a_{1}=\frac{b(1-\beta)}{(1+r)(k-f)}+\frac{\beta(f-w)}{k-f} \\
a_{2}=\frac{\beta(b-(1+r) f)}{k-f} \\
A_{0}=K_{0}^{c}\left(\frac{-a_{1}}{(1+g)}+\frac{-a_{2}}{(1+g)^{2}}\right)
\end{gathered}
$$

We can return to the dynamics of this system after first clarifying its dualism which becomes transparent in a pristine setting without the complications of a social security system.

\subsection{The Workers' Share of Wealth}

In the steady state, all elements of the capital stock grow at the same rate, which we can preliminarily assume to be $g$ :

$$
K_{+1}^{w}+K_{+1}^{G}+K_{+1}^{c}=(1+g) K
$$

The share of government-owned wealth is a policy target, equal to $f / k$. From Equations (8) and (9), it follows that the share of worker-owned wealth is given by

$$
\frac{K^{w}}{K}=\frac{\phi}{1+g}
$$


Thus, if there is a steady state with growth determined by the Cambridge equation, the distribution of wealth is easily obtained.

\section{A Basic Model of the Pasinetti Paradox}

\subsection{Dynamics}

For expositional and comparative purposes, it is useful to consider first the simplest case in which there is no social security system. In this case, workers' lifetime wealth reduces to the wage, or $h^{\prime}=w$. (We use primes to identify specialized values of the parameters $h$ and $\phi$, and assign new symbols for specialized values of the other parameters.) By setting $f=b=\tau=0$ in Equation (12), we can see that the dynamic behavior of the system is captured by a first-order difference equation describing workers' wealth,

$$
\begin{gathered}
K^{w}-\phi^{\prime} K_{-1}^{w}=A_{1}(1+g)^{t} \\
\text { where } \phi^{\prime}=\frac{w \beta}{k} \\
A_{1}=\frac{\phi K_{0}^{c}}{(1+g)}
\end{gathered}
$$

In this special case, the workers' growth factor has a natural economic interpretation as the growth rate that would obtain in a world without capitalists, or in other words the growth rate generated exclusively by the life-cycle saving of workers ${ }^{9}$. This can be seen by returning to Equation (8) and setting all variables attached to the government or the capitalists to zero. 
From the non-negativity of $\phi^{\prime}$ it is clear that the movement of $K^{w}$ will be monotonic. Finding the general solution by the method of undermined coefficients, and starting from some initial conditions in year 0 we have

$$
K^{w}=\left(K_{0}^{w}-\frac{\phi^{\prime} K_{0}^{c}}{1+g-\phi^{\prime}}\right) \phi^{\prime t}+\left(\frac{\phi^{\prime} K_{0}^{c}}{1+g-\phi^{\prime}}\right)(1+g)^{t}
$$

Obviously, the difference equation will be dominated by the larger of the capitalist growth factor, $1+g$, and the workers' growth factor, $\phi^{\prime}$. If the workers' growth factor dominates, the share of workers' wealth will asymptotically approach unity because it is growing faster than capitalist wealth.

On the other hand, if the capitalist growth factor dominates, the rate of growth of workers' wealth will approach that of capitalists, $g$, and in the steady state workers will own a constant proportion of a capital stock steadily increasing at the rate of growth dictated by the Cambridge growth equation. This regime thus exhibits a version of the Pasinetti Paradox since changes in the workers' growth factor have no effect on the long-run rate of growth as long as they remain within the limits defined by the capitalist growth factor. Unlike the traditional Kaldor-Pasinetti result that the profit rate is invariant to changes in workers' saving, derived under the assumption of an exogenous labor-constrained growth rate, we find that it is the growth rate which displays invariance to changes in workers' saving under the assumption of endogenous capital-constrained growth. 


\subsection{Alternative Regimes}

\subsubsection{Kaldor-Pasinetti-Robinson}

Let us assume that the capitalist growth factor exceeds the workers' growth factor, so that the second regime described above prevails. In the steady state, we will find a stable division of the total capital stock between workers' wealth, $K^{w}$, and capitalist wealth, $K^{c}$. From Equation (14) specialized to this case, the workers' share of wealth is

$$
\frac{K^{w}}{K}=\frac{\phi^{\prime}}{1+g}
$$

With the workers' growth factor less than the capitalist growth factor, we enter a Kaldor-Pasinetti-Robinson regime in which the Cambridge equation determines the long-run growth rate of the economy and the thriftiness of workers expresses itself in the workers' share of total wealth. This does not mean that workers' saving lacks importance. A decrease in workers' saving will reduce the workers' share in total wealth by decreasing the amount of workers' wealth. Since it will not affect the path of capitalist wealth, this implies that a decrease in workers' thrift will lower the overall level of capital, output and employment, without affecting the long run growth rate of any of these variables. This is an important point, to which we return when we find that social security similarly has level but not growth effects in the two-class model.

\subsubsection{Samuelson-Modigliani}

The alternative possibility might be described as a Samuelson-Modigliani regime in which capital accumulation driven by a thrifty working class swamps 
a dynasty of profligate capitalists. This occurs when the workers' growth factor exceeds the capitalist growth factor, as we have seen. In the limit, the share of wealth owned by workers will approach unity. The 1960s saw controversy over the plausibility of these two regimes. We know considerably more about the patterns of wealth accumulation in the U.S. and other advanced economies, and it is now impossible to deny the existence of a fairly large amount of purely capitalist, bequest-originating wealth ${ }^{10}$.

A cursory analysis shows how much workers would have to save to achieve the Samuelson-Modigliani regime under modern conditions. Write the workers' growth factor as

$$
\phi^{\prime}=\beta(1-\pi) \rho
$$

We cannot observe $\beta$ directly but we can observe $1-\pi$, the wage share, and $\rho$, the output-capital ratio. These have values in the range of $0.6-0.8$ and 10-20 per generational period (perhaps 25 years) respectively, in modern advanced economies. Thus, since the growth factor is on the order of 2.6 per generational period, workers would have to save over 25 per cent of their lifetime earnings in order for $\phi^{\prime}$ to exceed $1+g$. Later we will return to this question in a calibration exercise designed to illuminate, among other topics, the controversy over how much of the capital stock originates in the life cycle saving of workers. In the remainder of this paper, we will assume that the conditions for the Kaldor-Pasinetti-Robinson model obtain. 


\section{A Classification of Funding Systems}

The existence of a social security system raises the issue of how it is financed. The predominant mode of finance is payroll taxes ${ }^{11}$ on active workers, but most real systems include some kind of reserve fund or trust fund. Before developing the alternative systems in any detail, it is useful to provide a systematic classification of their distinguishing features. Recall that we have chosen to target the level of benefits and the per-worker reserve fund. With these values held constant, we can derive the relationship between the reserve fund and the tax in a steady state equilibrium (where the growth rate equals g) from Equation (5). Table 1 presents the full spectrum of permissible fiscal systems, assuming a steady state equilibrium with $b$ and $f$ held constant.

[Table 1 goes here]

In the absence of any reserve fund, the tax must be sufficient to cover benefits fully. Since the taxable base of workers is growing at the same rate as the capital stock in the steady state, the effective yield on taxes will be the long-run growth rate. Comparisons between the effective yield on social security taxes and the return on equities are often made polemically by conservative opponents of social insurance, but all they really prove is that the system is not fully funded.

A modest reserve fund defines a partially-funded social security system. In this case, the tax need not be so large, and the effective yield is higher than it would be under pay-as-you-go. At some point when the fund becomes large enough to fully fund the system, the tax contribution becomes equivalent to saving at the market rate of return. Since a fully funded system returns 
taxpayers the same rate that they would obtain by investing in real capital, it is easy to show that it would collapse into the Basic Model treated in the previous section.

Beyond the fully funded level, the reserve fund and the income it generates subsidize participants in the social security system enough that the yield on their payroll taxes exceeds the market rate of return. We call this a "superfunded" system. If funding is large enough, it can eliminate the need for taxes altogether and in fact could permit the payment of negative taxes to workers. The rationale for a superfunded social security system is that it offers a practical vehicle for the redistribution of wealth and for the generation of capital formation under conditions of democratic control.

The existence of a social security fund necessitates a period of primitive accumulation, during which taxes exceed benefits. If this surplus is built up from the payroll taxes of workers, it implies a kind of forced saving in which one or more generations of workers contribute to a fund which benefits future generations. The other potential source of revenue is a tax on capitalists. This need not be limited to the current flow of profits, since the capitalists have assets that can be transferred to government ownership. We could imagine, for example, a once-for-all tax on capitalist wealth or a capital levy, the proceeds of which are dedicated to a permanent reserve fund for workers. We can gain a better appreciation of this issue after we have an understanding of the behavior of an economy which has already experienced the primitive accumulation of a reserve fund. 


\section{An Unfunded Social Security System}

In an unfunded social security system, benefits are financed entirely through taxes on the pay-as-you-go principle. From Equation (5) with $f=0$, we have

$$
\tau=\frac{b}{1+g_{-1}^{K}}
$$

It is clear from Equation (15) that a period of below-normal growth in capital expresses itself in low employment and high taxes in the next period, a dynamic which is painfully familiar to the most recent generation of U.S. workers who entered the labor market during a period of slowing growth and who must pay for a baby boom generation which began working during the Golden Age of Capital Accumulation in the 1960s.

With this fiscal policy, the expression for lifetime wealth is now

$$
h^{\prime \prime}=w-b\left(\frac{1}{1+g_{-1}^{K}}-\frac{1}{1+r}\right)
$$

A constant level of benefits and taxes in a steady state reduces workers' lifetime wealth $\left(h^{\prime \prime}<h^{\prime}\right)$ because the rate of profit exceeds the rate of growth. Including social security does not change our earlier conclusion that workers consume a constant fraction of their lifetime wealth, but it does change the value of the workers' growth factor, which is now written

$$
\phi^{\prime \prime}=\frac{w \beta}{k}-\frac{b}{k}\left(\frac{\beta}{(1+g)}+\frac{1-\beta}{(1+r)}\right)
$$

The presence of a social security system reduces the workers' growth factor $\left(\phi^{\prime \prime}<\phi^{\prime}\right)$ because it reduces their lifetime wealth. 


\subsection{Steady State}

We can characterize the steady state exactly as before, in terms of the equilibrium value for the workers' share of social wealth (i.e., the capital stock) from Equation (14). The new expression is simply

$$
\frac{K^{w}}{K}=\frac{\phi^{\prime \prime}}{1+g}
$$

The social security system reduces workers' share of social wealth by discouraging life-cycle saving. But as we saw in the Basic Model for a change in workers' thrift, a reduction in workers' saving does not affect the longrun growth rate of the system, which continues to be determined through the Cambridge equation without reference to their behavior at all. Social security has level effects on the capital stock owned by workers, and on the employment provided by that part of the capital stock. In fact, in the calibration exercise below we estimate the magnitude of these level effects in the U.S. Since this is such a sensitive issue, (the putative "third rail" of American politics), we should state clearly that real social security systems generate benefits which are not included in this simple representation, such as insurance against disability and progressive income transfers that have effectively reduced widespread poverty among the elderly. Any losses calculated in this paper have to be stacked up against these palpable benefits by readers exercising good judgment.

\subsection{Dynamics}

The dynamic behavior of the system is again dominated by the workers' capital stock. The workers' capital stock obeys a second-order difference 
equation, which is just Equation (12) specialized for $f=0$ :

$$
\begin{gathered}
K^{w}+c_{1} K_{-1}^{w}+c_{2} K_{-2}^{w}=A_{2}(1+g)^{t} \\
\text { where } c_{1}=\frac{b(1-\beta)}{k(1+r)}-\frac{w \beta}{k} \\
c_{2}=\frac{b \beta}{k} \\
A_{2}=K_{0}^{c}\left(\frac{-c_{1}}{(1+g)}+\frac{-c_{2}}{(1+g)^{2}}\right)
\end{gathered}
$$

We need to check for stability to be sure there is no hidden implausibility that would jeopardize the comparative equilibrium analysis. For parameter values chosen to calibrate the model to the U.S. economy (see notes to Table 2 ), the three necessary and sufficient conditions for stability of the homogeneous second-order difference equation associated with Equation (12) are easily satisfied. Even though the roots of the difference equation lie within the unit circle, (i.e., the stability conditions are satisfied), they will be complex if the discriminant, $D=c_{1}^{2}-4 c_{2}$, is less than zero, a condition which appears fairly easy to satisfy for likely parameter values and benefit levels ${ }^{12}$. Thus, it is quite plausible that a model calibrated to real economies would display damped oscillations after some shock, such as a change in benefit levels. These oscillations are caused by the mechanical fiscal policy in place since a period of above-normal growth will be followed by a period of lower taxes, which increases workers' wealth and saving. Although the "cycles" are at frequencies well below those of the traditional business cycle, it would not be inaccurate to describe this fiscal system as an automatic destabilizer. 


\section{A Calibration Exercise}

Since nearly all the parameters in this model have observable counterparts, it should be possible to calibrate the model to real economic data, to check for gross plausibility, to re-interpret the controversy about the relative importance of life-cycle and bequest saving, and to assess the impact of social security on the capital stock. The one parameter which is not observable is the workers' discount factor, but since it must lie within the unit interval, the range of possible predictions for the workers' share of wealth (which is equivalent to the share of life-cycle wealth) can be delimited. The data upon which the calibration exercise in Table 2 relies have been assembled from the Penn World Tables and other easily accessible sources, assuming a generational period of 25 calendar years.

[Table 2 goes around here]

We know from the literature on the distribution of wealth by saving motive that the range of estimates is quite broad. Modigliani (1988) for example insists that life-cycle saving accounts for the great bulk of capital accumulation in the U.S., perhaps as much as 80 per cent. This estimate has been challenged, most notably by Kotlikoff and Summers (1981), who find that as little as 20 per cent of the wealth stock originated in saving out of earnings. Not surprisingly, more recent research has tended to report estimates midrange between these extremes; for example Gale and Scholz (1994) find that under 50 per cent of wealth originates in life cycle saving.

The calibration exercise in Table 2 shows the predicted workers' share of wealth, both with and without consideration of social security wealth, for a 
range of workers' savings propensities. With the parameter values in Table 2 , the system escapes the Kaldor-Pasinetti regime for values of $\beta$ greater than .29 with an unfunded social security system and .27 in absence of social security. Even accepting Modigliani's estimate that 80 per cent of wealth is generated by life cycle saving, the implied value of $\beta$ is just over .2 with an unfunded system, well within the Kaldor-Pasinetti range. It is important to be aware that the controversy about the extent of life cycle wealth does not call into question the validity of the two-class model. From the perspective of this model, the debate concerns not whether but the extent to which the capitalist growth factor exceeds the workers' growth factor. Even if Modigliani is right about the preponderance of life cycle wealth, we are still apparently living in a Kaldor-Pasinetti-Robinson world. Of course, such a simple calibration exercise is no substitute for an exhaustive statistical investigation (for example, taking precautionary saving and unintentional bequests into account), so these comments need to be discounted appropriately. The most important lesson is that the two-class model does not generate any wildly implausible predictions, which entitles us to feel some measure of confidence in its analytical power.

The final column of Table 2 reports the calculated effect of social security on the total capital stock. This is possible because social security does not affect the path of capitalist wealth, which permits us to calculate the change in total capital from the change in the workers' share of wealth alone. Recall that in principle social security has a level effect but not a growth effect. The procedure is to first calculate the implied size of capitalist wealth for each value of $\beta$ assuming an unfunded social security system, and then to 
use these values to calculate the amount of workers' wealth which would prevail in the absence of social security ${ }^{13}$. This estimate of workers' wealth is added to capitalist wealth to produce an estimate of total wealth in absence of social security. The log difference between this estimate and the observed capital stock represents the percentage change in wealth due to social security shown in the last column of Table 2. These level effects are modest - on the order of 7-10 per cent - for low values of the workers' discount rate, but they become quite substantial as the discount rate approaches the top of its range, reaching the 60 per cent reduction that Feldstein (1996) claims for the effect of social security. Thus, the controversy over the distribution of wealth by source has substantive policy implications which can be readily appreciated within the two-class model.

\section{A Partially-Funded Social Security System}

Let us now consider the implications of a social security system which operates a permanent reserve fund, using the interest or profit on governmentowned capital to supplement taxes in financing benefits.

\subsection{Dynamic Fiscal Policy}

Recall that the dynamic fiscal policy in place commits the government to maintaining a constant level of government-owned capital per worker, $f$, and a constant level of benefits made possible by using the tax as the policy instrument. Again, this is a mechanical policy, but it does lead to a dynamic solution which serves to validate the comparative equilibrium results in which 
we are most interested. Note that this policy implies a constant share of government-owned capital in total capital, which commits the government to keeping pace with the vagaries of private capital accumulation.

This fiscal policy remains in the automatic destabilizer family for small values of $f$, meaning that a period of above-normal growth is followed by a period of low taxes, although it becomes less destabilizing as $f$ increases. When $f>b /(1+r)$, the policy changes form and assumes a pro-cyclic automatic stabilizing role, but the tax in a partially-funded system never gets this large. The tax in a partially-funded system must satisfy $\tau>b /(1+r)$ which implies that $f<b /(1+r)$ as well. Nonetheless, the existence of a fund can eliminate oscillatory behavior by effecting a sign change in the discriminant.

\subsection{Lifetime Wealth and the Steady State}

By reducing the tax burden, a permanent fund increases workers' lifetime wealth $\left(h>h^{\prime \prime}\right)$, as we can see in Equation (6). Similarly, in Equation (9) we can see that a reserve fund increases the workers' growth factor $\left(\phi>\phi^{\prime \prime}\right)$ because workers saving increases in response to greater lifetime wealth. The share of wealth owned by workers continues to be described by Equation (14). Thus the existence of a reserve fund will increase the workers' share of the capital stock by increasing their lifetime wealth and stimulating greater saving.

The practical importance of the point that a permanent reserve fund increases workers' saving is that it makes the estimates achieved through the calibration exercise of the previous section an upper bound for the effects of 
social security on the workers' share of wealth. The present system operates with a trust fund, and although this is mainly an instrument of dynamic fiscal policy designed to smooth the transition between cohorts of differing sizes, it does have a semi-permanent quality. Calibrating the model would be difficult since the observed data have not originated in a steady state.

\subsection{Dynamics}

The dynamics of the system remain transparent since the fiscal policy commits the government to imitate the pattern of workers' accumulation in order to maintain its target share of wealth, $f / k$. This means that the government's behavior collapses into that of workers' and capitalist households, and the dynamics of the system remain tied to Equation (12), the second-order difference equation which describes workers' capital holdings.

For realistic parameter values and levels of the trust fund, this system remains stable in terms of the roots of the difference equation. Indeed, because the dynamic fiscal policy responds less sharply to swings in accumulation it will be less destabilizing (prone to oscillations) than the fiscal policy for an unfunded system, much as a car with shock absorbers can comfortably negotiate potholes. Formally, the discriminant is an increasing function of $f$, which can cut the horizontal axis from below at permissible levels of $f$. Thus, the trust fund acts as a shock absorber insofar as increases in its size can transform a system displaying damped oscillations into one which converges monotonically on its steady state after a perturbation ${ }^{14}$. 


\section{A Fully Funded Social Security System}

A fully funded social security system collapses into the Basic Model in terms of workers' consumption, as we have noted. This can be proved easily by substituting the defining condition for full funding, $f=b /(1+r)$, into Equation (6) for lifetime wealth, which resolves into $h=w$, exactly as in the Basic Model. Thus, the workers treat their tax payment as a form of saving, and they consume and save (in this extended sense) exactly as they would in the absence of a social security system. Looking at this from another angle, in the fully funded case, where $\tau=b /(1+r)$, paying taxes is equivalent to saving at market rates.

This social security system is not, however, completely neutral with respect to capital accumulation, because it is being partially financed out of government-owned capital stock which had to be accumulated in some earlier periods. The combined share of worker-owned and government-owned capital, from Equations (13) and (14), is given by

$$
\frac{\phi}{1+g}+\frac{f}{k}=\frac{\phi^{\prime}}{1+g}+\frac{f g}{k(1+g)}
$$

This expression illustrates that in the presence of full reserve funding the combined share of workers and government will exceed the workers' share of wealth in the Basic Model by the amount of the second term on the RHS. (Recall that $\phi^{\prime} /(1+g)$ is the workers' share of wealth in the Basic Model.) The capitalists' share of wealth will be correspondingly lower. This nonneutrality result alerts us to the significance of the primitive accumulation of the reserve fund, a topic to which we return below. 


\section{A Superfunded Social Security System}

As a final exercise, it is useful to consider a social security system which is so well-funded that workers receive a yield on their tax contribution in excess of the market rate of return on capital. Obviously, no real system comes close to such a pattern, but the exercise has some value beyond the amusement of economists because it focuses attention on the reserve fund as a potential vehicle for accomplishing egalitarian political goals. Such a fund could be established through payroll taxes, so that one or more generations of workers contributes to the welfare of future generations. It could also be established through a tax on the assets of capitalists, as a practical method for effecting a progressive redistribution of wealth.

The reserve fund per worker must exceed $b /(1+r)$ before the yield on tax contributions exceeds the market rate of return. Using the parameter values for the calibration exercise, this implies a level of permanent reserve funding equal to around $\$ 8600$ per worker (in constant 1987 dollars). It is even possible to imagine that a sufficient fund has been accumulated for workers to avoid paying social security taxes altogether or even to receive a negative payroll tax during their working years. The required tax vanishes when the level of reserve funding reaches $b /(r-g)$, and beyond that level the tax becomes negative. Using the parameter values from the calibration exercise, this occurs at a level of permanent reserve funding over $\$ 17,600$ per worker. Obviously, there is a broad range of funding levels in between these two values wherein workers would enjoy a subsidy which makes paying taxes much like putting money in a mutual fund that consistently outperforms the market. The political attraction of such a straightforward mechanism for 
redistributing wealth should be readily apparent.

The share of wealth owned by workers continues to be described by Equation (14). We have already seen that increasing the reserve fund raises the workers' growth factor, because it contributes to their lifetime wealth and stimulates saving. It follows that the workers' share of wealth would continue to increase with further additions to the reserve fund.

A superfunded system raises the question of limits on the size of the reserve fund given by the combined share of wealth owned by workers and government. To find the limit on the reserve fund given by the share of wealth owned by workers and government, note that in order to leave some proportion of wealth to be owned by capitalists, it must be true that

$$
\frac{\phi}{1+g}+\frac{f}{k}<1
$$

The first term on the left-hand side of this expression is, of course, the workers' share of wealth and the second is the government's share of wealth. At some level, reserve funding threatens to increase the government and workers' share of wealth beyond this limit, pushing the system through a qualitative change into a Modigliani-Samuelson regime. With the parameter values in the calibration exercise above, the critical amount of reserve funding is $f=\$ 49,000$ when $\beta=.05$, and $f=\$ 8,000$ when $\beta=.25$. For comparison, the social security trust fund in 1989 held assets worth just over $\$ 1,300$ per worker (Social Security Administration, 2001, Table VI.A4), suggesting that this limit is not very close at hand. 


\section{Increases in the Reserve Fund}

We are now well-prepared to examine the implications of an increase in the reserve fund ${ }^{15}$. The following remarks apply equally to a system which becomes fully funded or superfunded as to one which remains partially funded. For clarity, the discussion assumes that some target level of funding is achieved starting from scratch in an unfunded system, although the conclusions apply to any increase in reserve funding. Thus, the exercise compares the transitional path to a steady state equilibrium after the primitive accumulation of a reserve fund (called the test path) with the path of an economy in steady state equilibrium with an unfunded system paying the same level of benefits (called the control path).

\subsection{Taxes on Workers}

If the primitive accumulation of the reserve fund is based on payroll taxes, the path of workers' capital will first drop before growing at the steady state rate from a new, lower base. The stock of government-owned capital will first increase before converging on the steady state growth path. Since the government does no consuming, the increases in government-owned capital will more than compensate the loss of workers' capital, and the total capital stock will therefore experience a level increase, which makes good sense in light of the forced saving by one or more generations of workers which initiated the change. Formally, as we have seen in the discussion of fully funded social insurance, an increase in the reserve fund will increase the share of government-owned capital as well as the workers' share of capital, and re- 
duce the share of capitalist wealth correspondingly. Since it will have no effect on the path of capitalist wealth, it is clear without formal proof that in the steady state the total capital stock on the test path must exceed the capital stock on the control path.

\subsection{Taxes on Capitalist Wealth}

If the primitive accumulation of the reserve fund is based on a tax on capitalist wealth, it will increase workers' lifetime wealth and generate additional workers' saving but at the same time it will reduce capitalist wealth and saving. The net result will typically be an increase in aggregate capital, because this policy redistributes wealth from capitalists who consume some of it to a government committed to preserving it. We can demonstrate this by first focusing on the impact effect of a one- period lump-sum tax, $\tau_{c}$, levied on capitalist wealth in period 0 , starting from a steady state equilibrium. From Equation (4), we can see that workers' saving will increase above its level on the control path by $\beta \Delta \tau$, where $\Delta \tau$ is the reduction in the payroll tax made possible by the newly established reserve fund. The reserve fund per worker, $f$, will equal $\tau_{c} k / K_{0}$, and the change in the tax will be $-f(r-g) /(1+g)$ from Equation (5). (Since we start in a steady state, the lagged growth rate is $g$.) Thus, the difference between the test level and the control level of workers' saving in period 1 is

$$
\Delta K_{1}^{w}=\tau_{c}\left(\frac{\beta(r-g)}{1+g}\right)
$$

Notice that the difference in workers' saving vanishes when $r=g$ because in this case there is no tax reduction. 
The tax reduces capitalist wealth to $K_{0}^{c}-\tau_{c}$. With the log utility function, capitalist consumption will remain a constant fraction of end- of-period wealth ${ }^{16}$. Capitalist saving on the test path will be

$$
K_{1}^{c}=\beta_{c}(1+r)\left(K_{0}^{c}-\tau_{c}\right)=(1+g)\left(K_{0}^{c}-\tau_{c}\right)
$$

Thus, after-tax capitalist wealth continues to grow at the rate $g$. The difference between the test and control levels of capitalist saving is then easily calculated from Equation (1):

$$
\Delta K_{1}^{c}=-\tau_{c}(1+g)
$$

Finally, the reserve fund does not exist on the control path so that the difference between the test and control levels of government capital is

$$
\Delta K_{1}^{G}=\frac{f}{k-f}\left(K_{1}^{w}+K_{1}^{c}\right)=\tau_{c}\left(\frac{K_{1}^{w}+K_{1}^{c}}{K_{0}^{w}+\left(K_{0}^{c}-\tau_{c}\right)}\right)
$$

The term on the extreme right of this expression represents the growth factor for the privately-held after-tax capital stock, denoted by $1+g^{P}$, where

$$
1+g^{P}=\frac{K_{1}^{w}+K_{1}^{c}}{K_{0}^{w}+\left(K_{0}^{c}-\tau_{c}\right)}
$$

We have already determined that workers' capital will grow faster in period 1 than $g$ as the result of the reserve fund and that capitalist after-tax wealth will grow at the rate $g$. It follows that $g^{P}>g$ unless $g=r$, in which case $g^{P}=g$.

By summing the differences in each component of the capital stock given by Equations (16)-(18), we arrive at an expression for the difference between 
the test and control levels of aggregate capital, i.e., the impact effect of a tax on capitalist wealth:

$$
\Delta K=\tau_{c}\left(\frac{\beta(r-g)}{1+g}+\left(g^{P}-g\right)\right)
$$

It follows immediately that

$$
\Delta K \geq 0 \Leftrightarrow r \geq g
$$

or, in other words, that a one-time lump-sum tax on capitalist wealth will generate additional capital formation in the first period after it is levied unless capitalist consumption is zero, in which case it will have no effect. The effect of such a tax in the steady state will have the same sign as this expression, because after this first period, capitalist wealth continues to grow at the rate $g$ while the growth rate of workers' wealth converges from above on $g$ in the long run.

The closest thing in practice to a lump-sum tax on capitalists is a oncefor-all progressive wealth tax or capital levy. The capital levy has been sporadically discussed over the last century and even implemented (to retire war debt) on rare occasions (Eichengreen, 1989). Whether such a policy is economically or politically feasible (for example, whether the fear of a repeated capital levy would increase the capitalist discount factor or otherwise discourage accumulation to a greater extent than our model suggests) is a separate question that would obviously need to be addressed in practice. A progressive or socialist government might consider the social security reserve fund as a potential vehicle for achieving some of the traditional goals of socialism and egalitarianism. Whether or not it is combined with the long-term 
goal of superfunding, progressively redistributing wealth into the social security reserve fund offers the potential for generating broad political support because it raises the effective yield on payroll taxes.

\section{Policy Implications of Endogenous Growth}

We make the assumption of an endogenous supply of labor primarily to learn more about the properties of the model when distribution is exogenous, since so much of the literature on social security and growth makes the polar opposite assumption that labor supply constrains growth. On the other hand, there are features of the labor supply in real economies which would support the assumption of the endogeneity of labor supply. First, real capitalist economies enjoy flows of immigration which have historically satisfied a substantial proportion of their labor force needs, and these flows are effectively controlled through immigration policies that arguably respond to employers' interests in maintaining access to labor resources ${ }^{17}$. Over the last decades, the policy dilemmas of governments in the high-income nations have typically concerned managing a surfeit of immigration rather than overcoming a deficit. Second, the market sector of modern economies is surrounded by important non-market or quasi-market sectors, such as home production, which have historically served as long-term sources of labor, through increased participation by women in waged labor for example. Third, mass unemployment frequently (one could even say normally) creates the possibility for accommodating some growth by simply putting the jobless into work. Fourth, a relationship between fertility and incomes can hardly be denied, as the 
spectacle of declining birth rates and falling living standards in the formerly socialist countries grimly reminds us. The assumption of an exogenous wage does no more violence to the complexities of the labor market than does the assumption of an exogenous supply of labor.

Labor limitations on growth have been and certainly can be of practical significance, but it is useful to see how the process of capitalist accumulation proceeds unencumbered by such limits. This point is of fundamental importance for the analysis of policies like social security. The traditional method for setting policy, for example the approach taken by the Trustees of the U.S. Social Security System in projecting the fiscal needs of the system, implicitly uses the Solow-Swan growth model as its analytical framework. In that framework, since the effective future labor force is predestined, fiscal policy can only effect change through movements along the putative neoclassical aggregate production function.

The Trustees of the U.S. Social Security System typically input a range of projections for the future labor force and technological change in generating forecasts for future fiscal needs of the system. Their most recent projections assume that slower technological change and demographic trends will reduce the growth of GDP to the range 2.4-1.3 per cent per year over the next three decades, from 2001 to 2030, and even lower for the years beyond (Social Security Administration, 2001, Table V.B.2). For comparison, the capital stock and GDP in the Penn World Tables (Summers and Heston, 1991) grew at the respective rates of 3.9 and 2.8 per cent per year from 1965-1990. If we assume that technological change will be Harrod-neutral over the projection period, the Trustees' projections imply that capital accumulation will fall 
to a level ranging from one-third to three-fifths of its former value. From the Classical perspective such a large decline in accumulation would need to be justified, either in terms of reduced profitability or some diminished propensity to invest. These differences could thus have massive implications for policy making that should be explored, but this paper sticks closely to the first order of business which is to elaborate carefully and precisely a Classical model of endogenous growth with overlapping generations of workers.

\section{Discussion}

The purposes of writing out such a stylized and simplified model as the two-class model which frames this paper include working out the logical implications of important policy and parameter changes and interpreting the observations from real economies in all their complexity. By combining a dynastic capitalist class with overlapping generations of workers who save for retirement, we have been able to interpret the range of estimates on offer for the shares of wealth in the U.S. that can be attributed to life cycle saving and bequests, and to analyze the comparative equilibrium effects of changes in workers' saving, for example, those brought about through social security. The range of estimates for the share of life cycle wealth suggests that growth depends critically on the existence of a capitalist class which accumulates wealth for bequest purposes. This confirms the vision of the Classical economists and their modern followers who have continued to insist that any clear thinking about capitalist society must acknowledge the existence of a distinct class of capitalists. 
In our model within the realistic range of parameters, the long run growth rate of the economy depends only on the profit rate and the saving propensity of capitalists. Changes in the saving propensity of workers reflect themselves in changes in the steady state share of the capital stock owned by workers. By reducing their lifetime wealth, the imposition of an unfunded social security system reduces workers' saving and brings about a level effect on the capital stock, leaving the long run growth rate unchanged. Our calibration exercise suggests these effects may well be overstated by economists who neglect or underestimate bequest saving.

A partially-funded system mitigates against the reduction in capital accumulation. Moving from an unfunded system to a funded system by means of forced saving out of payroll taxes permanently increases the capital stock in this model because in addition to enlisting the government in the accumulation process it augments workers' lifetime wealth and stimulates greater life cycle saving. The same move engineered by means of a one-time tax on capitalist wealth also augments workers' lifetime wealth and stimulates life cycle saving, and although it reduces capitalist saving, we have shown that the net effect on capital accumulation is non-negative in our model. Reserve funding reduces the payroll tax required to finance given benefits, and at some point this subsidization can even become sufficiently generous that the return on payroll taxes equals or exceeds the return to capital. A policy aimed at accumulating reserves through the taxation of capitalist wealth might attract broad political support since it increases workers' lifetime wealth in a transparent way, is favorable to life-cycle saving, and may foster a greater overall level of capital accumulation in the bargain. 


\section{References}

Congressional Budget Office 1998. Social Security and Private Saving: A Review of the Empirical Evidence, CBO Memorandum, Washington, D.C.

Council of Economic Advisors 1998. Economic Report of the President, Washington, DC: U.S. Government Printing Office

David M. and Menchik P.L. 1985. The effect of social security on lifetime wealth accumulation and bequests, Economica, volume 52, no. 28, pp. $421-434$

Diamond P. 1965. National debt in a neoclassical growth model, American Economic Review, volume 55, no. 5, pp. 1126-1150

Eichengreen B. 1989. The Capital Levy in Theory and Practice, National Bureau of Economic Research, Cambridge MA, working Paper No. 3096

Fazi E. and Salvadori N. 1985. The existence of a two-class economy in a general Cambridge model of growth and distribution, Cambridge Journal of Economics, volume 9, no. 2, pp. 55-164

Feldstein M. 1974. Social security, induced retirement, and aggregate capital accumulation, Journal of Political Economy, volume 82, no. 5, pp. 905-926

Feldstein M. 1996. Social security and saving: New time series evidence, National Tax Journal, volume 49, no. 2, pp. 151-164

Foley D.K. and Michl T.R. 1999. Growth and Distribution, Cambridge MA: Harvard University Press 
Gale W. and Scholz J.K. 1994. Intergenerational transfers and the accumulation of wealth, Journal of Economic Perspectives, volume 8, no. 4, pp. $145-160$

Gullason E.T. Kolluri B.R. and Panik M.J. 1993. Social security and household wealth accumulation: Refined microeconometric evidence, Review of Economics and Statistics, volume 75, no. 3, pp. 548-551

Harcourt G.C. 1972. Some Cambridge Controversies in the Theory of Capital, Cambridge UK: Cambridge University Press

Kaldor N. 1956. Alternative theories of distribution, Review of Economic Studies, volume 23, no. 2, pp. 83-100

Kessler D. and Masson A. eds. 1988. Modelling the Accumulation and Distribution of Wealth, Oxford: Clarendon Press

Kotlikoff L.J. and Summers L.H. 1981. The role of intergenerational transfers in aggregate capital accumulation, Journal of Political Economy, volume 89 , no. 4 , pp. $706-732$

Krueger A.B. and Pischke J.S. 1992. The effect of social security on labor supply: A cohort analysis of the notch generation, Journal of Labor Economics, volume 10, no. 4, pp. 412-437

Marglin S.A. 1984. Growth, Distribution, and Prices, Cambridge MA: Harvard University Press

Michl T.R. 1999. Biased technical change and the aggregate production func- 
tion, International Review of Applied Economics, volume 13, no. 2, pp. $193-206$

Modigliani F. 1988. The role of intergenerational transfers and life cycle saving in the accumulation of wealth, Journal of Economic Perspectives, volume 2 , no. 2 , pp. $15-40$

Munnell A.H. 1974. The impact of social security on personal savings, $\mathrm{Na}$ tional Tax Journal, volume 27, no. 4, pp. 553-567

Pasinetti L.L. 1974. Growth and Income Distribution: Essays in Economic Theory, Cambridge UK: Cambridge University Press

Piore M.J. 1979. Birds of Passage: Migrant Labor and Industrial Societies, Cambridge UK: Cambridge University Press

Robinson J. 1964. Essays in the Theory of Economic Growth, New York: St. Martin's Press

Samuelson P.A. 1958. An exact consumption-loan model of interest with or without the social contrivance of money, Journal of Political Economy, volume 66, no. 6, pp. 467-482

Samuelson P.A. and Modigliani F. 1966. The Pasinetti paradox in neoclassical and more general models, Review of Economic Studies, volume 33, pp. 269-301

Smetters K. 1999. Ricardian equivalence: Long-run Leviathan, Journal of Public Economics, volume 73, pp. 395-421 


\section{Table 1. A Classification of Social Security Systems}

\begin{tabular}{ccc} 
Description & $f$ & $\tau$ \\
\hline unfunded & $f=0$ & $\frac{b}{1+r}<\tau=\frac{b}{1+g}$ \\
partially funded & $0<f<\frac{b}{1+r}$ & $\frac{b}{1+r}<\tau<\frac{b}{1+g}$ \\
fully funded & $f=\frac{b}{1+r}$ & $\tau=\frac{b}{1+r}$ \\
superfunded (a) & $\frac{b}{1+r}<f<\frac{b}{r-g}$ & $0<\tau<\frac{b}{1+r}$ \\
superfunded (b) & $f=\frac{b}{r-g}$ & $\tau=0$ \\
superfunded (c) & $f>\frac{b}{r-g}$ & $\tau<0$
\end{tabular}

Notes: Assuming a steady state equilibrium with growth rate $g$, constant benefit, $b$, and constant per-worker reserve fund, $f$. See text Equation (5).

Social Security Administration, 2001. Annual Report of the Board of Trustees, U.S. Government Printing Office, Washington DC

Summers R. and Heston A. 1991. The Penn World Table (Mark 5): An expanded set of international comparisons, Quarterly Journal of Economics, volume 106, no. 2, pp. 327-368 


\section{Table 2. Calibrating the Two-Class Model}

\begin{tabular}{c|cc|cc|c}
\hline 1 & 2 & 3 & 4 & 5 & 6 \\
$\beta$ & $\phi^{\prime}$ & $K^{w} / K$ & $\phi^{\prime \prime}$ & $K^{w} / K$ & $\Delta K / K$ \\
\hline .05 & 0.478 & .184 & 0.316 & .122 & .074 \\
.10 & 0.957 & .368 & 0.787 & .303 & .098 \\
.15 & 1.435 & .552 & 1.259 & .484 & .141 \\
.20 & 1.914 & .736 & 1.730 & .665 & .237 \\
.25 & 2.392 & .920 & 2.201 & .847 & .651 \\
\hline
\end{tabular}

Notes: $\phi^{\prime}$ and $\phi^{\prime \prime}$ represent the workers' growth factor without social security and with an unfunded social security system, respectively. This calibration uses the following values (per annum and in constant 1987 dollars where appropriate) for the U.S. in 1989, which are reported in Foley and Michl (1999, Tables 2.1 and 2.2)and originate in the Penn World Tables as extended by Adalmir Marquetti: $w=22,064, r=16.4 \%$ p.a., $k=56,997, \rho=$ $64.7 \%$ p.a., $1-\pi=59.8 \%, N=121.863$ million workers. In columns 2 and $3, b=0$. In columns 4 and $5, b=1,768$, which is equal to constant-dollar social security benefits in 1989, taken from Council of Economic Advisors (1998, Table B-78) divided by employment taken from the Penn Tables. The growth rate for the capital stock from 1965-1990, $g=$ $3.93 \%$ p. a., was calculated from the Penn World Tables. The generational period is taken to be 25 years. Column 6 shows the reduction in capital due to unfunded social security. For details about this and other computations, consult the text. 


\section{Notes}

${ }^{1}$ In this paper we focus on the pension aspects of social security systems despite the fact that real social security systems have insurance aspects and other features that are important.

${ }^{2}$ In this paper, we abstract from this problem and assume a fixed working life of one period. For recent empirical work that might be interpreted as supporting a modest role for social security in the intertemporal labor supply decisions of workers, see Krueger and Pischke (1992).

${ }^{3}$ Seminal contributions in the Classical tradition include Robinson (1964), Kaldor (1956), and Pasinetti (1974) while an important neoclassical rejoinder is Samuelson and Modigliani (1966). For an overview of this literature consult Harcourt (1972) or Marglin (1984) and for a modern generalization of the Pasinetti Paradox, see Fazi and Salvadori (1985).

${ }^{4}$ Write the Lagrangian $L=\left(1-\beta_{c}\right) \sum_{t=0}^{\infty} \beta_{c}^{t} \ln C-\sum_{t=0}^{\infty} \lambda\left(C+K_{+1}^{c}-\right.$ $(1+r) K^{c}$ ), where $\lambda$ are the Lagrangian multipliers (with time subscripts suppressed, as they are for the other dated variables). Then, from complementary slackness and the first-order conditions, $L_{C}=0, L_{K_{+1}^{c}}=0$, and $L_{\lambda}=0$, it follows that $C=\left(1-\beta_{c}\right)(1+r) K^{c}$. Details of this solution can be found in Foley and Michl (1999).

${ }^{5}$ The original Cambridge equation is written $g=s_{p} r$, where $s_{p}$ is the capitalist's average propensity to save out of profits. For the variant in the text the propensity to save out of wealth, $\beta_{c}$, is constant and the average propensity to save out of profits is an increasing function of the rate of profit. 
${ }^{6}$ Write the Lagrangian $J=(1-\beta) \ln c^{w}+\beta \ln c^{r}-\psi\left(c^{w}+c^{r} /(1+r)-h\right)$, where $\psi$ is the Lagrangian multiplier. The solution for $c^{w}$ follows from the first-order conditions, $J_{c^{w}}=0, J_{c^{r}}=0$, and $J_{\psi}=0$.

${ }^{7}$ In this paper, where we assume the absence of technical change in order to focus attention on essentials, this assumption presents no problems. Extending the model to include technical change would require some modifications, such as assuming that it is the wage share which is parametric. With this and other modifications (for example, measuring the wage in effective labor units), the results in this paper would be unchanged by the introduction of technical progress, as long is it remains of the Harrod-neutral variety which is exclusively consistent with the existence of a steady state.

${ }^{8}$ It would do no real harm were this technique to be selected from an infinite spectrum such as a constant-elasticity production function, although this approach has other problems which it would distract us to consider here. For an alternative interpretation of the production function which treats it as the residual historical record of a process of capital-using labor-saving technical change see Foley and Michl (1999, Ch. 7) or Michl (1999). For a discussion of the Classical model with a traditional production function, see Foley and Michl (1999, Ch. 6).

${ }^{9}$ For a model of endogenous growth in such an economy without capitalists, see Foley and Michl (1999, Ch. 13).

\footnotetext{
${ }^{10}$ See, for example, the essays contained in Kessler and Masson (1988)

${ }^{11}$ We use payroll tax to describe a tax whose incidence falls on wages, such
} 
as the U.S. FICA system.

${ }^{12}$ For example, with the parameter values from the calibration exercise below (see notes to Table 2), $D=-.04$ for $\beta=.05$ and $D=.38$ for $\beta=.1$.

${ }^{13}$ We use the fact that

$$
K^{w}=\left(\frac{K^{w} / K}{1-K^{w} / K}\right) K^{c}
$$

${ }^{14}$ For example, with the values used in the calibration exercise above and $\beta=.05$, a trust fund just over $\$ 2000$ per worker will raise $D$ to 0 , eliminating all oscillating behavior.

${ }^{15}$ Our analysis stops short of a full welfare analysis which would permit a Pareto-ranking of alternative policies or growth paths. One obstacle is that it not clear how to treat households who have no well-defined existence in the model on lower growth paths.

${ }^{16} \mathrm{To}$ see this, solve the capitalist programming problem with the budget constraint $C_{0}+K_{1}^{c} \leq(1+r)\left(K_{0}^{c}-\tau_{c}\right)$

${ }^{17}$ For an analysis that emphasizes the predominance of quantity signals over price signals in regulating flows of immigration, see Piore (1979). 